\title{
The Environmental Supply Chain Management and the Companies' Sustainable Development
}

\author{
Syed Abdul Rehman Khan \\ School of Economics and Management \\ Chang'an University \\ Xi'an, China \\ Sarehman_cscp@yahoo.com
}

\author{
Dong Qianli \\ School of Economics and Management \\ Chang'an University \\ Xi'an, China \\ 984730042@qq.com
}

\begin{abstract}
Due to the pressure from the public, government laws and environmental standards, companies have to emphasize on the environmental management. Using the experience of western and developed countries for reference and considering China's practical conditions. This article puts forward a proposal of carrying out sustainable supply chain management. By environmentally- Friendly practices in supplier selection and supply process and product design process, companies can grasp both economic and environmental advantages, and establish competitive edge in the international market.
\end{abstract}

Keywords-Green supply management; Economic performance; Enterprise development; Sustainable

\section{INTRODUCTION}

Many years ago, there is no concept of "environmental quality" in the world. With the social and economic development, the environmental quality refers to the clean air and clean water. At present, the concept of environmental quality has been extended to be the "safe drinking water, healthy ecosystems, safe food, non-toxic public places, safe waste management and restoration of contaminated sites" (Conference on Environmental Quality, 1996). At the same time, the general situation of the natural environment is also increasingly concerned by the public ${ }^{[1]}$. Manufacturing and production sectors produce a large number of wastes that have a large consumption of natural resources. The waste production rate far exceeds the earth compensation and recovery capability, causing the earth's ecological system fails to maintain a sustainable development. It thus has been the culprit of environment disruption ${ }^{[2]}$.

At present, companies are under pressure from all aspects of the environment. Above all, the pressure comes from the public. In the United States, around $75 \%$ consumers have stated that their consumer behavior is influenced by the corporate environment and $80 \%$ consumers are willing to pay the excess price for the environmentally friendly goods. An investigation of the environmental attitudes of the 22 countries around the world ${ }^{[3]}$ shows that: (1) More than half of these countries regard environmental problems as one of the three most serious problems; (2) In most countries, most people believe that environmental conditions affect their health and more people believe argue that the environment pollution affects the health of children. Citizens of 16 countries in 22 countries say they refuse to buy products that are harmful to the environment. As a result, we all know that environmental degradation is a global problem, we hope to reverse this trend, and we are willing to pay more for it. Second, the pressure comes from environmental regulations. In order to cater to people's growing concern about the environment (including pollution control and resource protection), all countries in the world have formulated relevant laws and regulations. The United States has developed a series of regulations ${ }^{[4]}$, for example: CAA (the Clean Air Act, 1967, 1970, 1977, 1990), CWA (the Clean Water Act, 1972, 1977, 1981, 1987), CERCLA (the Comprehensive Environmental Resource, Compensation, and Liability Act, 1980), TSCA (the Toxic Substances Act, 1976), SARA (THE Superfund Amendments and Re-authorization Act, the amendment of CERCLA, 1986) and EPCRA (the Emergency Planning and Community, 1986). China has also formulated a series of laws and regulations and has achieved certain results ${ }^{[5]}$. For instance, the Environmental Protection Law of the People's Republic of China (announced and implemented in 1989), Law of the People's Republic of China on the Prevention and Control of Atmospheric Pollution (approved in 1987 and implemented in 1988), National Law of Solid Wastes Environmental Pollution Control (approved in 1995 and implemented in 1996) and Law of the People's Republic of China on the Prevention and Control of Water Pollution (approved in 1984). Thirdly, the pressure comes from the International Organization for Standards (ISO 14000 Series). With the increasingly strict environmental regulations and the change of environmental management concept, the practice guide and standards are needed to develop correspondingly to help companies transform to the Ecosustainable business practices, ISO 14000 series therefore came into being. Recently, ISO uses ISO 14000 series as the world standard of environmental management system ${ }^{[6-7] \text {. }}$

\section{The Key to Sustainable DeVelopment of ENTERPRISES}

There is a new challenge of the global manufacturing enterprises in a new environmental era, that is, how to make the industrial production and environmental protection work together. At present, enterprises are not only required to deal with the waste by the public, they are also required to reduce the waste and carry out green management to produce the green products ${ }^{[8]}$. In the perspective of the laws and regulations of the countries (especially developed countries), it has experienced three stages: the first stage (during the end of 
1970s and the middle of 1980s) mainly focused on risk management, namely, waste management and pollution control; in the second stage (during the end of 1980s and the early 1990s), enterprises has entered into the pollution prevention and control phrase, they focused on how to reduce the use of materials, minimize the waste, minimization and improve efficiency; in the third stage (since the middle of 1990s), people have considered the life cycle management and industrial ecology, that is to maximize the profit and to ensure the quality of the environment, the focus is the environmental impact of the process and product life cycle. International Organization for Standards (ISO 14000 Series) has higher requirements for environmental protection, so the enterprises are required to pass the certification, so that they are able to enter the international market. Practice has proved that enterprises which enter the international market through the certification have received huge economic benefits. In China, many enterprises and government departments have attached great importance to certification, such as the Dalian Development Zone has published the financial support policy that aims at encouraging enterprises to implement ISO 14000 certification. This policy creates a series of convenient conditions for enterprises to achieve the environmental management system certification as soon as possible. So far, there are 13 companies successfully passed the certification in this region. In order to further advance the promotion of ISO 14000 series in this region, the Dalian development zone also passed the certification of ISO 14000 and made an example for other enterprises in 1999. The purpose of ISO 14000 is to encourage the formation of a unified global standard for environmental management; it can strengthen the ability of the enterprise to improve the performance of the measurement environment through continuous environmental auditing; it also strengthens the global trade and removes the trade barriers. The requirements of the enterprise are: making the advanced environmental impact analysis of all trading, products and processes; carrying out constant environmental impact assessment of current behavior, products and processes; penetrating the standards and objectives into the improvement of each organizational level, including the guidelines for pollution control and waste minimization; quantification of each agreed targets and the corresponding procedures; making corresponding disposal procedures when there are adversary conditions of environmental policy and unexpected emissions; and make sure there are equivalent programs of ISO for suppliers and contractors. Therefore, ISO 14000 shows the recent changes in the environmental theory. The concentrations of ISO 14000 are programs and systems, rather than the emission standards, restrictions and testing methods ${ }^{[7]}$.

In the face of this challenge, the first step is to redefine the supply chain management and integrate the environmental problems (such as minimum waste minimization and energy use) into the entire supply chain process. The concept of supply chain management has been put forward more than 20 years and the definition of supply chain also has different connotations in different periods. It was early viewed that the supply chain is an internal process of manufacturing enterprises and the concept is limited to the internal operation of the enterprise layer, which focuses on the use of enterprise's own resources. Later, the concept of supply chain attaches more important the connection with other enterprises and the external environment, which is regarded as a "conversion process, in which the raw materials are converted into products and consumption through the manufacturing, assembly, distribution, retail and other processes of the enterprise". Recently, the concept of supply chain, however, pays more attention to the network chain of the core enterprise, such as the relationships among core enterprise and supplier, the supplier of supplier, the user and the user's user ${ }^{[9]}$.

\section{IMPLEMENTATION OF GSCM}

At present, enterprises cannot ignore environmental issues any more. In face of the government's decrees and the growing public pressure, the environmental issues must be incorporated into the corporate planning agenda. At the same time, companies are adjusting their supply chain processes to lower costs and better meet customer needs. These two trends are mutually linked. Enterprises must include their supplier and sales targets into the scope of management to meet or even surpass the requirements of the government and the public. As a matter of fact, how to establish green supply chain is the key to achieve this goal. Some well-known multinational companies successfully take the green supply chain management as the enterprise culture and penetrate it into all processing aspects, all departments and all staff, such as Ford automobile company, Hewlett-Packard Co, Procter \& Gamble and General Electric Group. In this paper, we try to discusses to bring the supplier into the process of environmental management and three aspects of the implementation of environmental friendly-practically practices, namely, product design process, material selection and supply process optimization enterprise ${ }^{[10]}$.

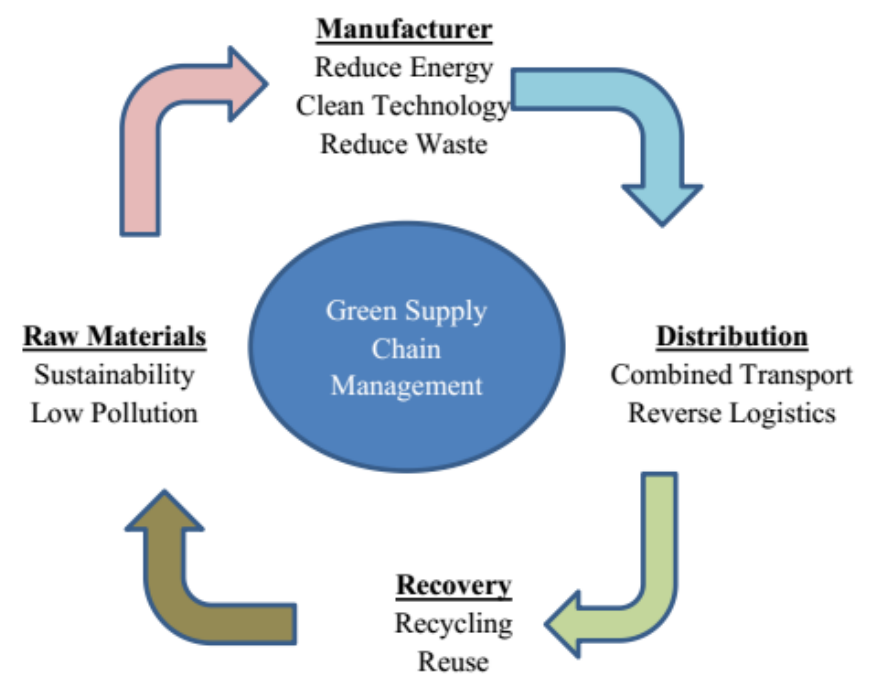

Fig. 1. Green Supply Chain Management

\section{A. Product Design Process}

One of the approaches to improve the material specifications is to strengthen the mutual understanding between suppliers and designers. Numerous enterprises have committed to re planning the design process and implemented the "design for the sake of environment". Some enterprises set 
up a "product design group" to discuss environmental issues in the design of new products. The design group mainly analyzes through the life cycle, in order to research all inputs and outputs materials and the processing of byproducts and the potential possibilities and methods once at end of the life cycle. The vast majority of well-known multinational companies regard the law as a challenge, as well as an opportunity. They think that if you can effectively make the use of the law and under the circumstance of maintaining the company's basic foothold, you are able to create a considerable environmental benefit in accordance with the law. Some domestic run-well businesses attach great importance to environmental problems in the product design process, such as FAW Dalian diesel engine factory. The basic purpose of the product design engineering department is to meet the requirements of environmental protection firstly, while the economic benefit is secondary. The new products are required to outside the current international regulatory requirements. It is because of the sufficient attention of environmental issues in design process, the enterprise has established a good image and reputation, and ultimately achieved good economic benefits.

Considering the environmental problems in product design, we have to discuss all material's life cycle, strengthen the communication between designers and materials experts, and use some scientific methods, such as life cycle analysis, quality foundation development and DFE, etc.

\section{B. The Selection of Product Materials}

The product design and development process are required to include the purchase behavior of enterprises and the supplier's behavior for the sake of the DFE (Design for the Environment). In addition, the environmental design of supplier is closed related to the environmental management of purchaser, because both sides belongs a part of the supply chain management.

Now, many companies are concerned about the selection of product materials in the design process, such as the use of low odor materials of furniture companies. In 1993, the United States requested mark the products which release the ozonedepleting substances. Nowadays, the ODS is prohibited by Environment Protection Agency in the United States. The enterprises which have beforehand altered to use other replacements have not been affected, but enterprises which failed to make the innovation have been in trouble. Ford has successfully put the environmental concept into the selection of cost materials, which not only brought the environmental benefits, established a reputation for the company, more importantly, brought considerable economic benefits. In 1999, the resource recycling revenue of Ford reached $\$ 1$ billion. The outermost shell of Ford cars and many other components are made of cans, plastic bottles and other recycled materials. Besides, Ford souvenir T-shirt is also made by $50 \%$ recycled cotton and $50 \%$ plastic bottles.

It is also an important part to minimize the materials types in the supply chain management. In the past, many companies used a variety of materials in one kind of product, which has brought difficulties in the recycling that has received widely concern. In addition, it is increasingly important to use alternatives to reduce waste generation and reduce the consumption of raw materials. At present, there is a good example to replace the logs with plywood in the construction industry. This innovation not only makes full use of the raw materials and in line with environmental protection requirements, but also improves the fineness of product, as well as become very popular among consumers.

Therefore, it is imperative to change the use of raw materials specifications in the design process and prevent the use of hazardous materials which has been prohibited by the law in the green supply chain management. According to the APCIS-US, (2013) Companies should use to the reverse hierarchy for better sustainable development of organizations. In the reverse logistics hierarchy, Redue is the priority option; reduce to the hazardous, toxic and dangerous materials in the end-to-end supply chain.

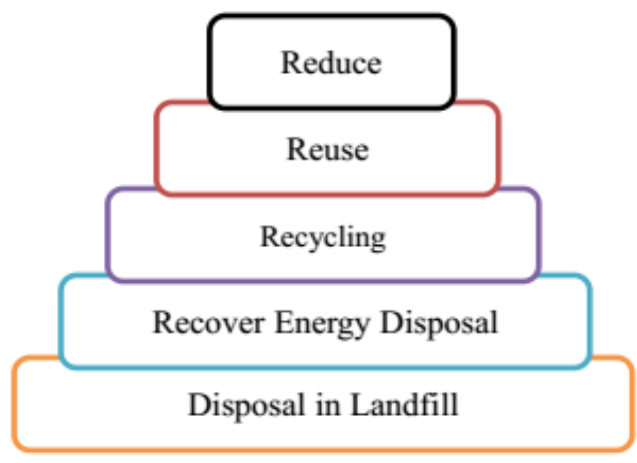

Fig. 2. Hierarchy of Reverse Logistics

\section{The Optimization of the Supply Chain Process}

Most companies have realized the impact of procurement on environmental friendly practices. Active suppliers focus on the improvement in environmental friendly practices, which has a significant impact on the supply chain. American furniture companies claim that the suppliers are required to provide the wood from the sustainable development forest and do not use some harmful tropical timber, such as mahogany. The purpose is to reduce the waste and the use of materials through the communication with the supplier and making requirements of their products. For instance, many companies have demands on the length of a product, so as to reduce the amount of residue after consumption. In the United States, some companies use their evaluation system to monitor the supplier's environmental process, they even send vice president to particularly deal with of the environmental problems. Xerox Corp. has always attached great importance to customer needs. Their products are not only reliable and efficient in quality, more importantly, the company focuses on customer's requirements in the product development, in the hope of reducing the by-product after consumption, concerning about the product's efficiency and environmental benefits, and reducing the damage on the environment to the most extent. It is because of the positive attitude of Xerox Corp, "win-win" among the demand party, the customer and the whole environment. It is very common in the United States. 
The supplier assessment and company's internal logistics management are the two most critical aspects in the supply process.

\section{A. The Scientific Evaluation of Suppliers}

In order to actually include the supplier into environmental friendly practices, close ties in trade partners must be established. Suppliers may have two kinds of attitudes toward EPC planning. If the supplier does not cooperate, the enterprise shall prepare how to remove the obstacles and plan accordingly. Enterprises are often difficult to convince the supplier, especially some scattered suppliers.

A survey of the United States shows that: materials managers believe that the prudent development of the supply assessment criteria is very important. They think that the ten important criteria in the environmental evaluation of the supplier are: (1) public disclosure in environmental records; (2) the EFP evaluation of the second tier supplier; (3) hazardous substance management; (4) pollution Management; (5) 17 hazardous materials required to be marked in EPA; (6) whether pass the ISO 14000; (7) reverse logistics plan; (8) EFP in product packaging; (9) ODS management; (10) hazardous gas emission management.

Even if a supplier voluntarily improves the environmental performance, it is still a confusing problem of how to successfully achieve the goal through their own observation or consumer's supervision. Therefore, the above ten standards are the first step to achieve the green supply chain management.

At present, multinational companies and domestic successful enterprises have attached great importance to the assessment of the supplier. For instance, the General Electric Cooperation initially pays too much attention to the cost of purchasing. Due to product quality is harmful to the environment, which greatly increases the processing cost in the later period in resulting in order to meet the requirements of environmental protection. Still, some final products are not able to meet the requirements. The companies has changed their strategy in recent years and greatly strengthened the environmental assessment of suppliers. If the supplier fails to meet the environmental protection requirements of GE Corp, then the GE will cancel the cooperation. Although this measure increased the procurement costs of the General Company, it greatly reduced the company's environmental input in the middle and later processing. What's more, it not only improves the quality of the final product, but also gained considerable economic benefits. FAW Dalian diesel engine factory attaches great importance to the evaluation of suppliers. They not only pay attention to collect the information of environmental conditions of suppliers and establish the supplier's database of main components. They are committed to establishing a longterm and stable cooperation with environmental friendly suppliers. It is because of the concentration on suppliers, the products of Dalian FAW diesel engine factory meet or surpass the current environmental regulations and win the confidence of upstream enterprises.

\section{B. Internal Logistics Management of Enterprises}

The changes of internal logistics can significantly reduce the pollution and cost. There is no denying that many enterprises have been committed to improving the internal logistics process. Some enterprises strengthen the environmental awareness of employees, so that employees are concerned about the procurement. In particular, the relevant environmental issues in packaging and internal logistics. In addition, a number of enterprises train their purchasers to make them abandon the fallacy of the unit-price based purchase and aware the significance of some other problems, such as processing and material waste. Some well-known multinational companies, such as GE Corp, they regard the environmental friendly performance of each employee as an important indicator in internal logistics management, which directly links to bonuses of each employee and accounted for a considerable proportion. It is because of the effective environmental-friendly practice of GE Corp, the cost of the enterprise is reduced, the enterprise reputation is improved, and it also received the government's approval and support and eventually gained considerable economic benefits in the achievement of sustainable development.

Nowadays, companies are beginning to use reusable packaging bags in purchase. For example, some of the furniture companies put the casters in reusable plastic plates instead of the plastic bags or carton boxes. This improvement not only reduces the use of packaging materials, but also provides a convenience for carriers. For instance, a company has replaced the metal box with cartons and saved 12 thousand dollars in only three years, while also reducing the number of cartons.

Therefore, the supplier should help enterprises to change the internal logistics process, thereby reducing waste (such as the packaging), which can also bring operational advantages, such as lower the cost and facilitate the transportation. It can be achieved by initiatively taking some measures, such as the reutilization of packages in transportation.

\section{CONCLUSION}

Green supply chain management is an effective way of enterprise's environmental management. The purchasing staff and supply chain managers play a key role in the green supply chain management of enterprises. The selection and evaluation of suppliers and the improvement of purchasing process, which play a fundamental role in establishing and maintaining competitive advantage of enterprise. In order to realize the green supply chain management, enterprises must firstly establish the green supply chain management concept, learn the advanced experience of developed countries, domestic and foreign enterprises or joint ventures, take the green management as the enterprise culture and penetrate it into all aspects of business, starting from the enterprise internal logistics management, and gradually establish the supplier files to realize the scientific evaluation on the suppliers. At the same time, enterprises also have to strengthen green management in product design and particularly in material selection to reduce the cost and achieve environmental standards. Furthermore, it is the urgent task to strengthen the construction of enterprise information and implement the green supply chain 
management. It is important to note that the implementations of green supply chain management are different in different industries and different enterprises. Therefore, the enterprises are required to take different approaches according to their actual situations, so as to reduce the cost, improve the benefit of environmental protection and corporate reputation, and ultimately increase profits to achieve sustainable development.

\section{REFERENCES}

[1] Fiksel J. Designing for environmental: Creating Eco-efficient products and processes [M]. New York: McGraw-Hill, 1996.

[2] Lamming R. and Hampson J. The environment as a supply chain issue [J]. British Journal of Management, 1996, (7): 45-62.

[3] Elkington J. Towards the sustainable corporation: Win-win-win business strategies for sustainable development [J]. California Management Review, 1994, 36(2): 90-100.

[4] Benita M. B. Designing the green supply chain [J]. Logistics Information Management, 1999, 12(4): 332-342.
[5] Gable, G., (1998) Large package software: a neglected technology, Journal of global information management, 6(3), pp. 3-4.

[6] Alexander F. ISO 14001: What does it mean for IE's [J]. IIE Solution, 1996, (1): 14-18.

[7] Pratt K.M. Environmental standards could govern trade [J]. Transportation and Distribution. 1997, (38): 68-76.

[8] Al-Mashari, M., Zairi, M., (1999) Standardization through SAP R/3: A proposed model for effective implementation. In: Proceedings of IEEE Conference on SIIT, pp. 19-24.

[9] Bhatt, G.D. (200) An empirical examination of the effects of information systems integration on business process improvement, International Journal of Operations and Production Management, Vol. 2, No. 11, PP. 1331-59.

[10] Steve V. W, Robert B. H. and Steven A. M. The green supply chain: integrating suppliers into environmental management processes [J]. International Journal of Purchasing and Materials Management, copyright April 1998, by National Association of Purchasing Management, Inc. pp 2-11.

[11] Industry Executive Advisory Team, Michigan State University Environmentally-Research. Manufacturing Research Team, These managers represents firms in the motive, computer, electronic, and consumer industries, 1997-12-03. 